\title{
PROSES ASSESSIBILITY AND DUCTING UTILITIES DENGAN PENDEKATAN LEAN CONSTRUCTION
}

\author{
Ade Astuti Widi Rahayu \\ Program Studi Teknik Industri, Universitas Buana Perjuangan Karawang \\ Jl. HS. Ronggowaluyo Telukjambe Timur, Karawang 41361 \\ Email: adeaswr@gmail.com
}

\begin{abstract}
ABSTRAK
Penelitian ini memiliki beberapa tujuan yaitu untuk melakukan analisis dan identifikasi aktivitas-aktivitas pada proses assessibility and ducting utilities, yang merupakan aktivitas yang menambah nilai (value added) dan aktivitas yang tidak menambah nilai (non value added) beserta nilai peningkatan dan reduksi waste, kemudian menyusun usulan perbaikan sistem proses assessibility and ducting utilities dan mengevaluasi kualitas hasil kerja yang dihasilkan, sehingga produktivitas perusahaan dapat tercapai. Metode yang digunakan adalah dengan menerapkan Lean Construction. Analisa proses Assessibility and Ducting Utilities menggunakan konsep Critical Path Method (CPM) dan Value Engineering (VE) dimulai dengan melakukan observasi yang di fokuskan pada tahapan proses Assessibility and Ducting Utilities. Penerapan Lean Construction telah berhasil mengevaluasi dan mengurangi waste yang terjadi pada proses assessibility and ducting utilities. Pemborosan terbanyak adalah pada proses penggalian. Upaya minimasi pemborosan pada proses penggalian adalah dengan cara mereduksi waktu tunggu dan reduksi biaya rental alat berat yang digunakan pada saat proses penggalian. Upaya perbaikan adalah dengan meniinimasi waktu dengan menggunakan CPM, yang dapat berkaitan dengan value dan rental alat.
\end{abstract}

Kata Kunci: Lean Construction, Value Added, Non Value Added, Critical Path Method $(C P M)$ and Value Engineering (VE)

\section{PENDAHULUAN}

Dunia konstruksi di Indonesia saat ini dihadapkan dengan proyek-proyek sangat rumit dan jangka waktu yang sangat singkat serta dituntut untuk memaksimalkan fungsi dengan biaya minimal dan tidak mengesampingkan kualitas. Untuk menghadapi tantangan tersebut dibutuhkan metode untuk meningkatkan efisiensi dan efektivitas dalam meningkatkan daya saing di dalam persaingan pasar industri konstruksi. Pembangunan sebuah proyek memiliki resiko yang cukup tinggi sehingga banyak faktor penting yang mempengaruhi hasil dari suatu proyek yang disebut dengan $7 \mathrm{M}$ menurut Ishikawa's Diagram, yaitu man, material, machine, method. measurement, management, dan milieu (Bergman \& Klefsjo, 2004). Namun industri konstruksi di Indonesia secara umum masih menghadapi permasalahan ketidakefisienan dalam tahap pelaksanaan konstruksinya, masih banyak pemborosan (waste) berupa kegiatan yang menggunakan sumber daya namun tidak menambah nilai (value). Pemborosan pada industri konstruksi sekitar 37\%, sedangkan kegiatan yang memberikan nilai tambah hanya sebesar 10\% (Lean Construction Institute, 2013). Kategori utama waste selama proses konstruksi dapat digambarkan sebagai: rework/perbaikan, cacat, material waste, 
penundaan, menunggu, alokasi bahan yang buruk, dan pemborosan material handling dan material yang tidak perlu (Alarcon, 1994).

Pada penelitian ini, cara yang digunakan yaitu konsep Lean Construction yang merupakan aplikasi dari konsep Lean Production System, dimana menitikberatkan pada pemaksimalan nilai (value) dan peminimalisasian pemborosan (waste) kepada teknik yang lebih spesifik untuk diterapkan dalam suatu proses yang baru dalam sebuah proyek.

PT KYG adalah salah satu perusahaan pelaksana proyek Accessibility and Ducting Utilities untuk Terminal 1 (T1) Bandara Soekarno Hatta Cengkareng Jakarta. Dalam melaksanakan proyek PT KYG sudah melakukan segala hal yang terbaik, namun ternyata masih menghadapi masalah yakni masih terdapat adanya waste atau non value added activities. Ditinjau dari segi teknis seperti adanya kesalahan pada saat penggalian, peralatan yang terkadang tidak berfungsi atau rusak, menunggu material yang datang, dan faktor cuaca juga mempengaruhi pemborosan waktu dalam pengerjaan proyek. Dikarenakan banjir maka pekerja harus memompa air banjir terlebih dahulu agar tidak mengganggu proses pengerjaan proyek. Padahal bobot pekerjaan yang paling banyak adalah di bagian ducting itu sendiri, yaitu sebesar 19,79 \% bila dibandingkan dengan aktivitas proyek lainnya (Sumber: Data Biaya Proyek Perusahaan 2016). Untuk memastikan agar tidak adanya keterlambatan dalam pelaksanaan proyek, PT KYG memberlakukan kerja lembur. Untuk waktu kerja normal adalah 8 jam kerja per hari menjadi 12 jam per hari. Hal ini dilakukan agar perusahaan dapa memenuhi kebutuhan konsumen.

Perusahaan memperkirakan ada beberapa pemborosan dalam proses konstruksi seperti biaya sewa pompa air mencapai $0.5 \%$ dari total biaya proyek, perbaikan akibat kesalahan penggalian mencapai $0.6 \%$ dari total biaya proyek. Jumlah waktu yang digunakan untuk aktivitas yang tidak menghasilkan nilai adalah $15 \%$ dari total waktu pelaksanaan proyek (Sumber: Data Biaya Proyek Perusahaan 2016). Hal tersebut membuktikan bahwa dalam menghasilkan nilai terdapat hambatan yang jelas yaitu pemborosan pada proses konstruksi. Permasalahan yang difokuskan dalam penelitian ini adalah bagaimana mengidentifikasi kegiatan yang tidak bernilai tambah (non value added activities) dan kegiatan yang bernilai tambah (value added activities) secara keseluruhan pada proyek assessibility and ducting dengan pendekatan Lean Construction, sehingga perusahaan dapat mengurangi waste.

\section{Perumusan Masalah}

Berdasarkan latar belakang di atas, maka permasalahan yang diangkat dalam penelitian ini adalah bagaimana mengidentifikasi dan meminimalkan waste yang terjadi pada proses assessibility and ducting utilities melalui pendekatan Lean Construction yang terkait dengan waktu dan biaya.

\section{Tujuan Penelitian}

Berdasarkan perumusan masalah sebagaimana tersebut di atas, maka tujuan penelitian ini adalah sebagai berikut ini: 
1. Melakukan analisis dan identifikasi aktivitas-aktivitas pada proses assessibility and ducting utilities, yang merupakan aktivitas yang menambah nilai (value added) dan aktivitas yang tidak menambah nilai (non value added) beserta nilai peningkatan dan reduksi waste.

2. Menyusun usulan perbaikan sistem proses assessibility and ducting utilities.

\section{TINJAUAN PUSTAKA}

\section{Manajemen Proyek}

Istilah manajemen proyek pertama kali muncul pada tahun 1953 di bidang kedirgantaraan Amerika Serikat (Johnson, 2006). Sejak manajemen proyek telah didefinisikan di banyak cara, bergantung dari jenis industri, organisasi, dan individu. Project Management Institute, Inc., (2013) menggambarkan manajemen proyek sebagai aplikasi pengetahuan, keahlian, alat, dan teknik untuk aktivitas proyek untuk menemukan kebutuhan proyek.

\section{2. lean Manufacturing}

Lean manufacturing populer dengan sebutan "Just-In-Time Manufacturing" yang dikembangkan oleh Toyota. Konsep ini sekarang digunakan oleh berbagai industri dan bisnis yang meliputi engineering, administrasi, manajemen proyek, dan manufaktur. Lean manufacturing bertujuan untuk mengubah suatu organisasi menjadi lebih efisien, berjalan dengan lancar, dan kompetitif. Aplikasi dari lean yaitu mengurangi lead time dan meningkatkan output dengan menghilangkan pemborosan yang timbul dalam berbagai bentuk (Gaspersz, 2011).

\section{Lean Construction}

Lean Construction menyajikan teknik sintesis koheren yang paling efektif untukmenghilangkan waste dan memberikan perbaikan perubahan biaya, waktu, kualitas dan keamanan yang signifikan secara bersamaan. Bahkan, lean construction memiliki banyak definisi: Ballard (2004) mendefinisikan lean sebagai: Nilai tambah dengan menghilangkan waste, menjadi responsif terhadap perubahan, berfokus pada kualitas, dan meningkatkan efektivitas kerja. Ballard dan Howell (2004) mendefinisikan: Sistem produksi sementara yang memberikan produk dengan nilai maksimum dan minimum waste. Sedangkan Lean Construction Insitute (2003) mendefinisikan lean construction: Sebuah manajemen produksi yang menggunakan pendekatan berbasis proyek pengiriman.

\section{Root Cause Analysis}

Root cause analysis merupakan sebuah metode evaluasi terstruktur untuk mengidentifikasi akar penyebab (root cause) suatu kejadian yang tidak diharapkan dan langkah-langkah yang diperlukan untuk mencegah terulangnya kembali kejadia yang tidak diharapkan. Untuk membuat suatu root cause analysis, bisa dilakukan dengan mengunakan The Five Why's (Bergman \& Klefsjo, 2004). Setelah mengetahui root cause dari permasalahan, dilakukan analisa selanjutnya untuk mengetahui penyebab kritis. Hasil dari RCA dapat pula dianalisis lebih lanjut dengan menggunakan FMEA (Failure Mode and Effect Analysis).

\section{The Five Why's}

The five why's sebagai bagian dari lean manufacturing, adalah teknik pemecahan masalah yang memungkinkan Anda untuk mendapatkan akar penyebab masalah cukup 
cepat (Bergman \& Klefsjo, 2004). Penerapan strategi dengan melibatkan pengambilan setiap masalah dan bertanya mengapa dan apa yang menyebabkan masalah ini.

Manfaat dari The Five why's adalah sebagai berikut:

a. Membantu untuk dengan cepat mengidentifikasi akar penyebab masalah.

b. Membantu menentukan hubungan antara akar penyebab yang berbeda dari masalah.

c. Dapat dipelajari dengan cepat dan tidak memerlukan analisis statistik yang akan digunakan.

\section{Pemborosan (Waste)}

Untuk mengidentifikasi waste, kita harus terlebih dahulu mengidentifikasi value, karena waste adalah segalah sesuatu yang menggunakan sumber daya (manusia, material, waktu) tanpa menciptakan nilai..

Terdapat delapan jenis pemborosan menurut Liker (2004), diantaranya sebagai berikut:

1. Menunggu (waiting/waste of time on hand)

2. Transportasi (transportation)

3. Proses yang berlebihan

4. Persediaan (inventory

5. Pergerakan (movement)

6. Cacat (defective part)

7. Kreativitas karyawan yang tidak dimanfaatkan

\section{Value Engineering}

Value Engineering menurut (Dell'lsolla, 1998) di industri konstruksi secara terorganisir untuk menantang disain dan konstruksi rencana proyek untuk memberikan fasilitas yang diperlukan dengan biaya keseluruhan terendah, konsisten dengan persyaratan untuk kinerja, kehandalan, dan pemeliharaan.

Di bawah, rumus menunjukkan hubungan antara nilai, kinerja dan siklus hidup biaya.

$$
V_{i}=\frac{P_{i}}{L C C_{i}}
$$

Dimana

$V i \quad$ : Nilai alternatif perbaikan $i$

$P i \quad$ : Performansi alternatif perbaikan $i$

$L C C i \quad$ : Siklus hidup biaya dari alternatif perbaikan $i$

Dalam proses Value Engineering, stakeholder proyek mengidentifikasi kriteria kinerja, membangun bobot relatif, dan kemudian menilai proyek ini. Tim Value Engineering menetapkan kinerja alternatif baru dibandingkan dengan kinerja proyek saat ini, dan para pemangku kepentingan proyek memverifikasi penilaian kinerja untuk alternatif Value Engineering.

\section{Value Analysis}

Saat ini, Value Analysis telah menikmati popularitas baru sebagai tekanan kompetitif yang memaksa perusahaan untuk memeriksa kembali rentang produk mereka 
dalam upaya untuk menawarkan tingkat yang lebih tinggi dari kustomisasi tanpa terkena sanksi biaya tinggi. Secara paralel, banyak perusahaan besar menggunakan proses Value Analysis dengan pemasok mereka untuk memperpanjang manfaat dari pendekatan seluruh rantai pasokan bisnis besar dan kecil, karena itu akan mendapatkan keuntungan dari memahami dan menerapkan proses Value Analysis. Sangat mungkin bahwa perusahaan-perusahaan yang tidak mengambil waktu untuk mengembangkan kemampuan ini akan menghadapi masa depan yang tidak pasti sebagai pelajaran dan masalah masa lalu yang didisain ulang menjadi produk masa depan.

Value Analysis (Analisis Nilai) menurut Rich et al. (2000) dapat didefinisikan sebagai proses review sistematis yang diterapkan pada produk disain untuk membandingkan fungsi dari produk yang dibutuhkan oleh pelanggan untuk memenuhi kebutuhan mereka pada biaya terendah, konsisten dengan kinerja tertentu dan kehandalan yang dibutuhkan.

\section{METODOLOGI PENELITIAN}

\section{Teknik Pengumpulan Data}

Teknik pengumpulan data yang digunakan dalam penelitian ini adalah teknik studi kasus. Data dikumpulkan untuk mengukur proporsi waktu dan langkah-langkah dalam setiap proses yang tidak bernilai tambah dan yang bernilai tambah. Sedangkan analisis data digunakan untuk memahami alasan kegiatan/proses yang tidak bernilai tambah dengan menggunakan cause effect analysis. Namun sebelumnya wawancara kepada pakar guna mengetahui permasalahan yang ada dalam proyek. Dalam hal ini diberikan pertanyaan kepada 4 orang yang memiliki pengalaman di bidangnya untuk memperoleh data yang berhubungan dengan hal yang mempengaruhi value dan waste. Kemudian memberikan solusi dan saran untuk mengurangi kegiatan yang tidak bernilai tambah dalam konstruksi.

\section{Teknik Analisis Data}

Teknik analisis data yang digunaan adalah dengan cara menerapkan prinsip lean construction. Standardisasi digunakan untuk mengurangi waste dalam proses untuk mengidentifikasi penyebab waste dan mengurangi sejumlah langkah yang tidak bernilai tambah. Berikut cara menerapkan prinsip lean construction:

a. Reduksi kegiatan yang tidak bernilai tambah (waste)

Pilih semua kegiatan yang tidak bernilai tambah menggunakan definisi yang diberikan oleh (Koskela, 1992) dalam bagian sebelumnya untuk fokus pada operasi kegiatan yang tidak menambah nilai. Kemudian Identifikasi 7 pemborosan (waste) yang ada dalam proses assessibility and ducting utilities dengan Cause Effect Analysis.

b. Peningkatan value berdasarkan dengan kebutuhan konsumen

Cara peningkatan value dengan cara mereduksi waste, sumber daya, biaya, dan waktu dengan menggunakan Value Engineering Analysis (VEA).

c. Pengurangan Variabilitas

Pengurangan variabilitas ini berkaitan dengan jadwal proses konstruksi. Critical Path Method (CPM) adalah alat yang digunakan untuk menganalisis jadwal dan akan dihubungkan dengan waste dan value.

\section{d. Bench Mark}

Perbandingan hasil waste dan value sebelum perbaikan dan setelah perbaikan. 


\section{Langkah-Langkah Penelitian}

Teknik analisis data yang digunakan berdasarkan pendekatan lean construction yang menitik beratkan pada beberapa jenis metode analisisnya yang terdiri dari Cause Effect Analysis, Value Engineering Analysis, dan Critical Path Analysis (CPM).

Adapun langkah-langkah dari penelitian dimulai dari identifikasi masalah dan tujuan, studi pustaka, pengumpulan data, penerapan lean construction, pembahasan, dan kesimpulan \& saran ini adalah sebagai berikut ini:

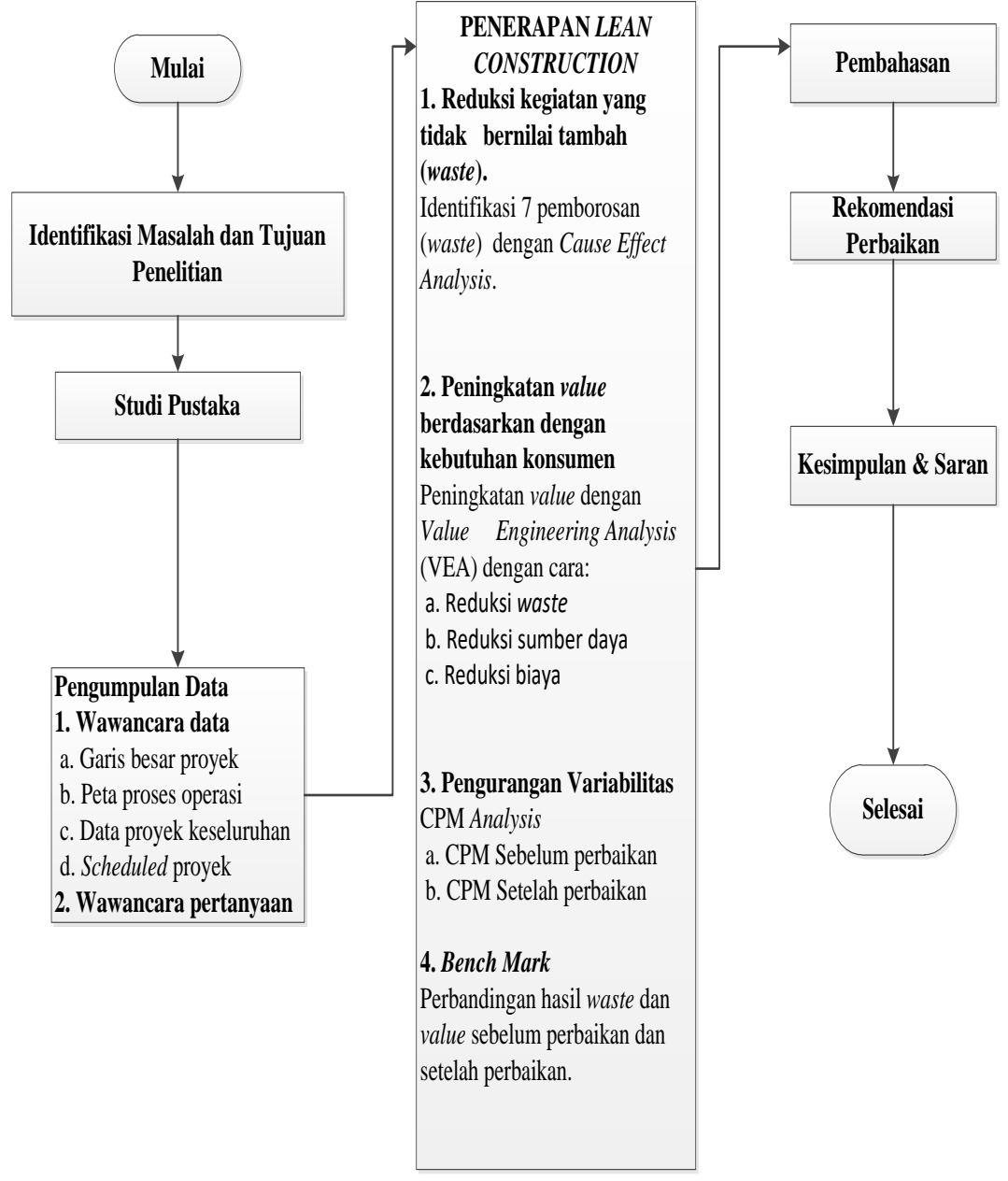

Gambar 1. Flow Chart Penelitian

\section{PEMBAHASAN}

Untuk mengevaluasi pemborosan (waste) yang ada pada perusahaan sesuai tujuan dari penelitian ini, maka perlu dilakukan usaha peningkatan value dan meminimasi waste pada proses konstruksi assessibility and ducting utilities. Dengan cara menganalisa faktor-faktor apa saja yang dapat menyebabkan waste dan bagaimana meminimasi waste. Hal tersebut perlu dilakukan suatu pendekatan pengendalian value dan waste dengan metode Lean Construction yang terstruktur dapat memperbaiki proses, fokus pada usaha untuk mengurangi variasi proses, reduksi biaya, dan sekaligus mengurangi pemborosan yang ada pada lini konstruksi. 


\section{Temuan Utama}

\section{Aktivitas VA dan NVA}

Adapun temuan utama yang sesuai dengan rumusan masalah bagaimana mengidentifikasi dan meminimalkan waste yang terjadi pada proses assessibility and ducting utilities melalui pendekatan Lean Construction yang terkait dengan waktu dan biaya adalah sebagai berikut ini:

1. Adapun analisis secara keseluruhan dari proses assessibility and ducting utilities bahwa jumlah Value Added yang ada adalah sebesar 40.54\% dan Non Value Added sebesar 59.46\% dengan total biaya Non Value Added Rp 37.000.000 atau sekitar $0.83 \%$ dari total biaya proyek keseluruhan.

2. Aktivitas Value Added terbanyak ada pada aktivitas persiapan dan pengecoran area yang berbelok. Sedangkan aktivitas Non Value Added terbanyak ada pada aktivitas penggalian, lantai kerja, dan pemasangan tray dan cable ladder. Akan tetapi aktivitas palinga berpengaruh terhadap Critical Path Method adalah proses penggalian dengan jumlah biaya Non Value Added sebesar Rp 60.000.000, disusul kemudian aktivitas pengecoran area yang berbelok sebesar $\mathrm{Rp} 5.000 .000$, dan penyambungan beton precast sbesar Rp 2.000.000.000.

3. Perbandingan jumlah Value Added sebelum perbaikan adalah sejumlah $40.54 \%$ dan Value Added sesudah perbaikan sejumlah $55.88 \%$ dengan cost sebesar Rp 198.000.000 atau 4.45\% dari biaya total proyek. Sedangkan untuk jumlah Non Value Added sebelum perbaikan adalah sebesar 59.46\% dan Non Value Added sesudah perbaikan adalah sejumlah 55.88\% dengan cost sebesar Rp 37.000.000 atau $0.83 \%$. Hal ini berarti bahwa Value Added setelah perbaikan meningkat $15.34 \%$, dan Non Value Added turun $3.58 \%$.

\section{Usulan Perbaikan}

\section{A. Saran Perbaikan Yang Berkaitan Dengan Waktu Dan Biaya}

1. Minimasi waktu dengan menggunakan CPM dapat berkaitan dengan value dan rental alat. Pada proses penggalian masing-masing alat mengalami reduksi waktu menunggu selama satu bulan. Hal ini secara otomatis berhubungan dengan biaya rental alat secara keseluruhan, dimana biaya sebelum reduksi sebesar Rp 1.330.000.000 menjadi Rp 1.095.000.000 dengan jumlah reduksi biaya sebesar Rp 235.000 .000 atau prosentase penurunan sebesar $17.67 \%$. Sedangkan untuk value dan rental alat pada pemasangan beton precast mengalami penurunan sebesar RP 30.000.000, yang semula Rp 300.000.000 menjadi Rp 270.000.000.

2. Dari tabel perbandingan jumlah waste dan value diketahui bahwa persentase total VA sebelum perbaikan adalah sebesar $40.54 \%$ dan sesudah perbaikan sebesar $44.12 \%$. Sedangkan untuk persentase total NVA sebelum perbaikan adalah sebesar $59.46 \%$ dan sesudah perbaikan sebesar $55.88 \%$. Hal ini berarti ada kesamaan jumlah selisih antara VA dan NVA sebelum dan sesudah perbaikan yaitu sebesar $3.58 \%$. Ini berarti bahwa VA setelah perbaikan meningkat sebesar $3.58 \%$ dan NVA turun sebesar $3.58 \%$.

3. Sedangkan untuk cost NVA sebesar Rp 37.000.000 atau sebesar $0.76 \%$ dari total biaya proyek keseluruhan, dan total cost VA sebesar Rp 198.000.000 atau 4.04\%. 
Hal ini menunjukkan bahwa penggunaan aplikasi Lean Construction dapat meningkatkan nilai VA sebesar $4.04 \%$ dengan penghematan biaya sebsar Rp 161.000.000.

\section{B. Saran Perbaikan Yang Berkaitan Dengan Waste}

\section{Waste yang berhubungan dengan sumber daya dan peralatan}

Waste yang berhubungan dengan sumber daya dan peralatan terdiri dari waiting, waste of motion, waste of extra processing, waste of transportation, dan skill labour.

\section{Waiting}

Kegiatan menunggu (waiting) dan sewa alat menjadi dua hal yang paling berkaitan dengan CPM. Semakin panjang durasi proyek, semakin banyak biaya yang dikeluarkan. Hal ini yang menyebabkan pemborosan. Kegiatan menunggu yang paling banyak ditemukan adalah pada proses penggalian. Proses ini memakan waktu tunggu pada perbaikan pompa penyedot air hujan dan perbaikan proses kerja karena kesalahan dalam penggalian. Tepatnya terkena kabel tegangan menengah dari instalasi lain. Sekali kena kabel TM membutuhkan biaya sebesar Rp 15.000.0000, sedangkan aktivitas ini sudah terkena kabel 2 kali yang berarti sebesar Rp 30.000.000.

Saran perbaikan dari pemborosan waktu karena perbaikan pompa adalah menggantinya dengan alat yang lebih sesuai dan cocok, memastikan bahwa alat dirawat sesuai prosedur, memastikan tersedianya suku cadang di proyek, atau mengganti dengan alat yang memiliki kapasitas yang besar. Untuk penggalian tanah yang terkena kabel tegangan menengah (TM) sebaiknya petugas instalasi sebelumnya terlebih dahulu menandai kabel-kabel instalasi dengan sebuah tulisan seperti "Instrumentation" disertai dengan warna yang mencolok, agar pada saat penggalian mudah dilihat oleh petugas di lapangan.

Kegiatan menunggu yang terbanyak kedua adalah pada proses pemasangan beton precast. Hal ini disebabkan karena beton yang akan diproses belum tersedia di site. Beton precast masih dalam proses pengerjaan di supplier. Karena sifat beton precast dibuat sesuai dengan hasil produksi supplier pada saat itu. Sedangkan nilai sewa alat yang paling banyak ditemukan pada proses penggalian, yaitu sebesar Rp 1.030.000.000, disusul proses pemasangan beton precast sebesar Rp 30.000.000. Saran dari masalah ini adalah aktif mengontrol proses pengiriman, melakukan pengecekan langsung ke lokasi material yang akan dikirim ke proyek, diusahakan memiliki lebih dari satu supplier, dan meninjau kembali atau merubah strategi kontrak pembayaran kepada supplier. Pada kontraktor yang terikat kontrak dengan harga tetap, umumnya kontraktor dibayarkan berdasarkan kemajuan atau progress kerja. Biasanya jumlah yang ditahan tersebut adalah $10 \%$ dari jumlah tagihan yang ditagih.

\section{Waste of motion}

Pemborosan gerakan dapat ditemukan pada aktivitas pemasangan tray dan kabel ladder. Gerakan antara pekerja yang satu dengan yang lainnya berbenturan pada saat pekerja sedang melakukan pengelasan tray. Hal ini disebabkan karena ukuran tren yang tidak terlalu besar, sedangkan di dalam tren itu sendiri sudah ada ladder-ladder yang terpasang. Selain itu agak sulit bagi pekerja untuk membawa peralatan ke dalam tren ketika akan mengelas. Pergerakannya harus hati-hati karena ada beberapa pekerja yang berbarengan mengelas. Saran perbaikan dari masalah ini adalah meringkas peralatan yang ada di site, maksudnya peralatan yang tidak berguna agar tidak diikutsertakan dalam pengerjaan tray, seperti kabel-kabel yang menghalangi pergerakan. Selain itu 
diusahakan agar ada komunikasi dan koordinasi yang baik antara tim pekerja mengenai penunjukan bagian yang akan dilas, agar gerakannya tidak saling berbenturan.

\section{Waste of extra processing}

Pemborosan pemprosesan yang berlebih maksudnya disini adalah proses penyedotan air yang mengenang akibat dari hujan yang turun. Proses ini seringkali dilakukan secara berulang-ulang. Saran perbaikan dari permasalahan ini adalah: membuat jadwal perkiraan hujan, memaksimalkan waktu pelaksanaan proyek, terutama pada jam yang sering kali tidak turun hujan (malam hari), memasang tenda/terpal untuk melindungi proses pelaksanaan pekerjaan, dan menggunakan alat keselamatan agar terhindar dari bahaya hujan turun, atau penggunaan blower fan atau lampu pijar untuk pengeringan pekerjaan.

\section{Waste of transportation}

Jauhnya jarak antara ruang penyimpanan barang dengan tempat bekerja menjadi salah satu pemborosan yang dapat mengulur waktu pada pengerjaan proyek, terutama pada aktivitas pemasangan tray dan kabel ladder. Para pekerja bolak-balik berjalan dari tempat penyimpanan besi siku ke tempat tren ducting berada. Saran perbaikan dari masalah ini adalah membuat tempat penyimpanan sementara yang dekat dengan tren, agar tidak menyebabkan pemborosan waktu proses.

\section{Skill Labor}

Pemborosan skill tenaga kerja pada proyek ini terjadi akibat tidak adanya update prosedur suatu pekerjaan dan kurangnya informasi mengenai teknologi penggunaan alat. Hal ini disebabkan karena kurangnya koordinasi antara pekerja dan atasan, tidak adanya shop drawing dari suatu pengerjaan tray atau ladder. Selain itu prosedur dalam proses pengerjaan ducting masih manual, sehingga kurangnya kesempatan pekerja untuk mengembangkan keterampilannya. Saran perbaikan dalam masalah ini adalah adanya pelatihan dan meeting antara atasan dan pekerja, agar didapatkan umpan balik yang saling bermanfaat.

\section{Waste yang berhubungan dengan material}

Waste yang berhubungan dengan material terdiri dari over production, inventory, dan defect.

\section{Inventory}

Pada proyek assessibility and ducting utilities tidak ada koordinasi atau aturan mengenai bagaimana seharusnya peralatan atau material diletakkan atau disimpan. Pekerja hanya sekedar meletakkan tanpa tahu dimana harus meletakkan, peralatan apa yang harus dijauhkan atau apa yang harus didekatkan. Saran perbaikan dari masalah ini adalah menerapkan 5S ditempat kerja, dengan cara sosialisasi 5S dan K3. Agar proyek berjalan dengan semestinya, tidak ada suatu kendala ataupun halangan yang merintangi. Misal saja peletakkan peralatan yang tidak pada tempatnya akan mengakibatkan kecelakaan kerja.

\section{Defect}

Pemborosan ini terjadi pada proses penggalian dengan jumlah biaya NVA sebesar Rp 60.000.000, disusul kemudian aktivitas pengecoran area yang berbelok sebesar Rp 5.000.000, dan penyambungan beton precast sbesar Rp 2.000.000.000. Hal ini disebabkan karena kesalahan pekerja. Faktor yang menyebabkan kesalahan dalam 
pengerjaan tersebut adalah dikarenakan adanya ketidaksesuaian pekerjaan dengan aturan pelaksanaan proyek. Seharusnya pada proses penggalian, petugas memeriksa dan mengamati secara detail bagaimana kondisi tanah yang akan digali dan apakah tanah yang akan digali tersebut sudah memiliki riwayat pengerjaan instalasi atau instrumentasi sebelumnya. Kemudian pada saat pekerja mengecor area tren ducting, ukuran material dan pengerjaan yang tidak sesuai akan mengakibatkan pengulangan pekerjaan. Begitu pula kesalahan yang terjadi pada saat beton precast disambung, tidak adanya kesesuaian ukuran material yang digunakan antara beton precast yang satu dengan yang lain. Saran perbaikan dari masalah ini adalah diperlukan kejelian dan inspeksi secara terus menerus pada ketiga bagian ini. Karena apabila ketiga bagian ini terlewatkan, akan fatal akibatnya dikemudian hari.

\section{KESIMPULAN}

Berdasarkan tujuan yang ada pada awal penelitian, maka diperoleh penelitian yang telah dilakukan, dan dapat disimpulkan sebagai berikut ini:

1. Penerapan Lean Construction telah berhasil mengevaluasi dan mengurangi waste yang terjadi pada proses assessibility and ducting utilities. Pemborosan terbanyak adalah pada proses penggalian. Upaya minimasi pemborosan pada proses penggalian adalah dengan cara mereduksi waktu tunggu dan reduksi biaya rental alat berat yang digunakan pada saat proses penggalian Adapun analisis secara keseluruhan dari proses assessibility and ducting utilities bahwa perbandingan jumlah Value Added sebelum perbaikan adalah sejumlah $40.54 \%$ dan Value Added sesudah perbaikan sejumlah 55.88\% dengan cost sebesar Rp 198.000.000 atau 4.45 $\%$ dari biaya total proyek. Sedangkan untuk jumlah Non Value Added sebelum perbaikan adalah sebesar $59.46 \%$ dan Non Value Added sesudah perbaikan adalah sejumlah 55.88\% dengan cost sebesar Rp 37.000.000 atau 0.83\%. Hal ini berarti bahwa Value Added setelah perbaikan meningkat 15.34\%, dan Non Value Added turun $3.58 \%$. Hal ini menunjukkan bahwa penggunaan aplikasi Lean Construction dapat meningkatkan nilai Value Added sebesar $15.34 \%$ dengan penghematan biaya sebesar Rp 161.000.000.

2. Upaya perbaikan adalah dengan meniinimasi waktu dengan menggunakan CPM, yang dapat berkaitan dengan value dan rental alat. Pada proses penggalian, masingmasing alat mengalami reduksi waktu menunggu selama satu bulan. Hal ini secara otomatis berhubungan dengan biaya rental alat secara keseluruhan, dimana biaya sebelum reduksi sebesar Rp 1.330.000.000 menjadi Rp 1.095.000.000 dengan jumlah reduksi biaya sebesar $\mathrm{Rp} 235.000 .000$ atau prosentase penurunan sebesar 17.67\%. Sedangkan untuk value dan rental alat pada pemasangan beton precast mengalami penurunan sebesar RP 30.000.000, yang semula Rp 300.000 .000 menjadi Rp 270.000.000. 


\section{DAFTAR PUSTAKA}

Dell'Isola, A. (1997). Value Engineering: Practical Applications for Design Construction, Maintenance \& Operations, John Wiley \& Sons Inc., New Jersey, USA.

Alarcon, L. F., (1994), Tools for the Identification and Reduction Waste in Construction Projects. Paper presented at the $2^{\text {nd }}$ International Workshop on Lean Construction, Santiago.

Alarcón, L. F., (1995), Training Field Personnel to Identify Waste and Improvement Opportunities, Paper presented at the $3^{\text {rd }}$ International Workshop on Lean Construction, Albuquerque.

Alwi, S., Hampson, K. and Mohamed, S. (2002a). Factor Influencing Contractors Performance in Indonesia: A Study of Non Value-Adding Activities. Proceedings of the International Conference on Advancement in Design, Construction, Construction Management and Maintenance of Building Structure, Bali, Indonesia.

Alwi, S., Hampson, K. and Mohamed, S. (2002b). Waste in the Indonesian Construction Project. Proceedings of the 1st International Conferences of CIB W107-Creating a Sustainable Construction Industry in Developing Countries, South Africa.

Alwi, Sugiharto. (2004). Training Field Personnel for Small to Medium Construction Companies: An Alternative Tool to Increase Productivity. In Proceedings The $12^{\text {th }}$ of the International Group of Lean Construction Conference, Copenhagen, Denmark.

Annappa, C. M, and Panditrao, K. S. (2014). Application of Value Engineering for Cost Reduction of Household Furniture Product - A Case Study. International Journal of Innovative Research in Science, Engineering and Technology, 3, 16577-16583.

Arbulu, R. and Zabelle, T., (2006), Implementing Lean In Construction: How To Succeed, In $14^{\text {th }}$ Annual Conference of the International Group for Lean Construcion, 1, 553-565. Santiago, Chile.

Atabay, S., and Galipogullari. (2013). Application of Value Engineering in Construction Projects. Journal of Traffic and Transportation Engineering, 1 (1), 39-48. 
Agyei, W., (2015). Project Planning and Scheduling Using Pert and CPM Techniques With Linear Programming: Case Study. International Journal of Scientific and Technology Research, 4, 22-227.

Bergman, B., and Klefsjö, B. (2004). Quality, from customer needs to customer satisfaction: Student litteratur Publishing.

Biswasa, S. K, Karmakera, C. L, and Biswasa, T. K. (2016). Time-Cost Trade-Off Analysis in a Construction Project Problem: Case Study. International Journal of Computational Engineering Research (IJCER), 6, 32-38.

Candido, L. F., Mahlmann, L. F., Netto, J. D. P. B. (2014). Critical Analysis on Earned Value Management (EVM) Technique In Building Construction. Proceedings IGLC-22, (pp.159-170). Oslo, Norway.

Chiang, T. A, Che, Z. H, and Zeng, B. J. (2015). The lean resources based construction project planning and control system. Joint International Conferences. Bari, Italy.

Ciampa, Dan. 1991. The CEO's Role in time-based competition. In: Blackburn, J.D. (Ed.). 1991. Time-Based Competition. Business One-Irwin, Homewood, IL.

Deepika, K., and Suchitthra. S., (2016). An Exploratory Study on Effective Time Management of a Project. International Journal of Current Trends in Engineering \& Research (IJCTER), 2, 151 - 157.

Ferrada, X.; and Serpell, A. (2009) Construction Methods Selection: Lessons Learned from Chile, Joint International Symposium W055 and W065, Dubrovnik, Croatia.

Gaspersz, V. (2011). Lean Six Sigma for Manufacturing and Service Industries. PT. Gramedia Pustaka Utama: Jakarta.

Heralova, R. S. (2016). Possibility of Using Value Engineering in Highway Projects. Proceedings of the Creative Construction Conference. Prague, Czech Republic: Czech Technical University.

Issa, U. H. (2013). Implementation of lean construction techniques for minimizing the risks effect on project construction time. Alexandria Engineering Journal, 52, 697-704. 